\title{
Precise Control of Intramolecular Charge-Transport: The Interplay of Distance and Conformational Effects
}

\author{
Christina Schubert, ${ }^{[\mathrm{a}]}$ Mateusz Wielopolski, ${ }^{[\mathrm{b}]}$ Lars-Hendrik Mewes, ${ }^{[\mathrm{a}]}$ \\ Gustavo de Miguel Rojas, ${ }^{[\mathrm{a}]}$ Cornelia van der Pol, ${ }^{[\mathrm{cc}}$ Kathryn C. Moss, ${ }^{[\mathrm{cc}]}$ \\ Martin R. Bryce, ${ }^{*[c]}$ Jacques E. Moser, $^{[b]}$ Timothy Clark, ${ }^{[d]}$ and Dirk M. Guldi*[a]
}

\begin{abstract}
A new series of donorbridge-acceptor (D-B-A) compounds consisting of $\pi$-conjugated oligofluorene (oFL) bridges between a ferrocene $(\mathrm{Fc})$ electron-donor and a fullerene $\left(\mathrm{C}_{60}\right)$ electron-acceptor have been synthesized. In addition to varying the length of the bridge (i.e., mono- and bi-fluorene derivatives), four different ways of linking ferrocene to the bridge have been examined. The Fc moiety is linked to oFL: 1) directly without any spacer, 2) by an ethynyl linkage, 3) by a vinylene linkage, and 4) by a $p$-phenylene unit. The electronic interactions between the electroactive species have been characterized by cyclic voltammetry, absorption, fluorescence, and tran-
\end{abstract}

sient absorption spectroscopy in combination with quantum chemical calculations. The calculations reveal exceptionally close energy-matching between the Fc and the oFL units, which results in strong electronic-coupling. Hence, intramolecular charge-transfer may easily occur upon exciting either the oFLs or Fcs. Photoexcitation of FcoFL- $\mathrm{C}_{60}$ conjugates results in transient radical-ion-pair states. The mode of linkage of the Fc and FL bridge has a profound effect on the photophysical

Keywords: charge transfer - cycloaddition $\cdot$ donor-acceptor systems • fullerenes $\cdot$ molecular wires properties. Whereas intramolecular charge-separation is found to occur rather independently of the distance, the linker between $\mathrm{Fc}$ and oFL acts (at least in oFL) as a bottleneck and significantly impacts the intramolecular charge-separation rates, resulting in beta values between $\beta_{\mathrm{CS}} 0.08$ and $0.19 \AA^{-1}$. In contrast, charge recombination depends strongly on the electron-donor-acceptor distance, but not at all on the linker. A value of $\beta_{\mathrm{CR}}$ $\left(0.35 \pm 0.01 \AA^{-1}\right)$ was found for all the systems studied. Oligofluorenes prove, therefore, to be excellent bridges for probing how small structural variations affect charge transport in D-B-A systems.

\section{Introduction}

Donor-bridge-acceptor (D-B-A) compounds have now served as model systems for understanding the charge transport between molecular entities in more complex architec-

[a] C. Schubert, L.-H. Mewes, Dr. G. de Miguel Rojas, Prof. D. M. Guldi Friedrich-Alexander-Universität Erlangen-Nürnberg

Department of Chemistry and Pharmacy

Institute for Physical Chemistry

Egerlandstr. 3, 91058 Erlangen (Germany)

E-mail: dirk.guldi@chemie.uni-erlangen.de

[b] Dr. M. Wielopolski, Prof. J. E. Moser

Écolé Polytechnique Fédérale de Lausanne

Institute of Chemical Sciences and Engineering

Photochemical Dynamics Group

Station 6, 1015 Lausanne (Switzerland)

[c] Dr. C. van der Pol, Dr. K. C. Moss, Prof. M. R. Bryce

Durham University, Department of Chemistry

Durham, DH1 3LE (UK)

E-mail: m.r.bryce@durham.ac.uk

[d] Prof. T. Clark

Friedrich-Alexander-Universität Erlangen-Nürnberg

Department of Chemistry and Pharmacy and

Interdisciplinary Center for Molecular Materials (ICMM)

Computer Chemistry Center (CCC)

Nägelsbacherstrasse 25, 91052 Erlangen (Germany)

Supporting information for this article is available on the WWW under http://dx.doi.org/10.1002/chem.201204055. tures such as the photosynthetic reaction center for many years. ${ }^{[1]}$ Investigations of D-B-A compounds have also provided a thorough knowledge base and a huge portfolio of molecular structures suitable for optoelectronics, solarenergy conversion, and emerging nanoscale applications. ${ }^{[2]}$ All of these processes have one crucial aspect in common, that is, a rapid and stepwise electron-transfer.

For this reason, it is of special interest to study the nature of charge transport in D-B-A systems, in which the length and chemical structure of the bridge are varied systematically. In particular, the bridge plays the role of a molecular wire that mediates the electronic coupling between donors and acceptors and, therefore, renders charge-transfer reactions possible over large distances, ${ }^{[2 a, 5 a, 3]}$ comparable to those in natural photosystems. ${ }^{[4]} \mathrm{A}$ common strategy for the design of molecules that can function as molecular wires is to incorporate $\pi$-conjugated oligomers in electron donor-acceptor conjugates. Many different oligomers have proved to be suitable wire-like linkers between donors and acceptors. These include, for example, oligo-phenylenevinylenes (oPVs),${ }^{[5]}$ oligo-phenyleneethynylenes (oPEs), ${ }^{[6]}$ oligo-fluorenes (oFLs), ${ }^{[7]}$ oligo-acetylenes (oligoynes) ${ }^{[8]}$ oligo-thiophenes ${ }^{[9]}$ oligo-vinylthiophenes ${ }^{[10]}$ oligo(ethynylene-10,20porphyrindiyl-ethynylene)s, ${ }^{[1]} \quad$ oligophenylenes, ${ }^{[12]}$ and others. ${ }^{[13,14]}$ It has been well-established that the electronic 
coupling between the donors and acceptors as mediated by the $\pi$-conjugated bridge decays exponentially with the distance between them. ${ }^{[15]}$ Thus, the rate of charge transfer, both charge separation and charge recombination, is also determined by an exponential expression:

$k_{\mathrm{CT}}=k_{0} e^{-\beta r_{\mathrm{DA}}}$

in which $k_{0}$ is a kinetic pre-factor, $r_{\mathrm{DA}}$ the separation distance between the electron donor and electron acceptor, and $\beta$ is the attenuation factor. The latter is often used to describe the capability of a $\pi$-conjugated wire-like oligomer to transport electrical charges. In accordance with the expression above, the value of $\beta$ should be as low as possible to promote rapid and efficient charge-transfer reactions. A low attenuation factor also means that the rate with which the charge is transferred does not depend on the distance between the donor and the acceptor. In such cases, the transfer of charges is comparable to tunneling. Generally, the $\beta$ value varies with the degree of conjugation. This not only includes the conjugation in the molecular bridge itself but also throughout the entire pathway that electrons traverse. In other words, a homogeneously conjugated bridge guarantees a low $\beta$ value only in the case of effective electronic-coupling to both the donor and the acceptor. The coupling depends strongly on the relative energy levels and energy gaps between donor and bridge as well as between bridge and acceptor. Several groups have therefore studied different oligomers bridging the same donor and acceptor components in comparable D-B-A systems. Wasielewski et al., for instance, have incorporated oligomers such as $p$ phenylenevinylene, ${ }^{[16]} p$-phenylene, ${ }^{[17]}$ and fluorene ${ }^{[18]}$ to bridge phenothiazine and perylene-3,4:9,10-bis(carboximide) as donors and acceptors, respectively. Here, the oligomeric $\pi$-conjugated bridges show a switch in the charge-transfer mechanism from super-exchange to hopping at longer bridge lengths. A more recent study ${ }^{[19]}$ compares D-B-A molecules, in which the same donor and acceptor are connected through fluorenone, $p$-phenyleneethynylene, and the previously reported $p$-phenylene. ${ }^{[20]}$

Another way to tune the donor-bridge/bridge-acceptor gaps and vary the coupling into the redox-active moieties is to modify the link between the bridge and the other components. To this end, differences in $\beta$ values are found for the same oligomer connected either to different donors and acceptors, or to the same donors and acceptors through different linking units. ${ }^{[21]}$ In both cases the matches between the donor-bridge and acceptor-bridge energy levels are refined. This affects the charge injection rates from the donor to the bridge and from the bridge into the acceptor. It is thus appealing not only to study the distance dependence of charge transfer, but also the impact of subtle variations of the linkers connecting the bridge to the donors and acceptors.

Previous work $^{[7]}$ showed that inserting a phenyl moiety between the donor and the bridge significantly alters the charge-transport properties of the bridge by modifying the $\pi$-conjugation pathway. In this particular case, hindering the homogenous $\pi$-conjugation by inserting a unit with slightly different electronic properties leads to an increase of $\beta$ for both charge separation and charge recombination. In another study, ${ }^{[2]}$ we reported systems in which $\mathrm{C}_{60}$ and exTTF are connected through oligo-vinylfluorenes (oVFL). The objective of this work was to probe the influence of a vinyl spacer in fluorene-based molecular wires. It turned out that combining the structural features of two types of molecular wires with extremely low $\beta$ values helped to improve the charge-transfer features of oligofluorenes. Thus, photoinduced electron-transfer investigations have shed light on the dependence of charge transport on the molecular structure of the bridge, the nature of the redox-active moiety, and its coupling to the linker.

We now report investigations of D-B-A systems, in which ferrocene $(\mathrm{Fc})$ donors and fullerene $\left(\mathrm{C}_{60}\right)$ acceptors are connected by oligo-fluorenes (oFLs) of various lengths. We have varied both the length of the bridge and the nature of the linkage between Fc and oFL by using four different ways of linking ferrocene to the bridge, namely 1) directly without any spacer, 2) by an ethynyl linkage, 3) by a vinylene linkage, and 4) by a $p$-phenylene unit (Figure 1). The thrust of these studies is to examine the influence of the different linking patterns on the intramolecular charge-transfer dynamics in solution. oFL bridges were chosen for their electronic properties. They provide $\pi$-conjugative electrontransport pathways with attenuation factors intermediate between oPVs and oPEs and are, therefore, ideally suited to be fine-tuned by structural changes. These studies also complement previous reports on D-B-A systems with oFL bridges and exTTF ${ }^{[22,23]}$ and Zn-porphyrin ${ }^{[7]}$ donors although they may not be compatible with oPV- and oPEbased D-B-A systems.

\section{Results and Discussion}

Synthesis: A series of Fc-spacer-oFL compounds was synthesized to probe the relationship between ferrocene $(\mathrm{Fc})$ and an oligofluorene (oFL) bridge. Ethynyl, vinyl, and phenyl spacers (2-4) were compared with reference $\mathbf{1}$, in which Fc is directly linked to the oFL bridge. Both mono$(n=1)$ and bi-fluorene $(n=2)$ bridges were synthesized to yield a set of eight compounds. A terminal-formyl group was added in all cases in preparation for the final step to the target electron-donor-acceptor conjugates $\mathbf{1 - 4}$, that is, the Prato 1,3-dipolar cycloaddition reaction ${ }^{[24]}$ of $\mathrm{C}_{60}$ with azomethine ylides formed in situ by treatment of the formyl group with sarcosine in chlorobenzene heated at reflux. An optimized ratio of $\mathrm{C}_{60} /$ sarcosine/formyl reagent of 4:5:1 was used. This gave the isolated adduct yields in the range of $48-68 \%$ with the practical benefit that the less-available formyl component is the limiting reagent.

Scheme 1 shows the syntheses of $\mathbf{1 a}$ and $\mathbf{1 b}$. Fluorene boronic esters $\mathbf{1 0} \mathbf{a}^{[25]}$ and $\mathbf{1 0 b} \mathbf{b}^{[25]}$ were treated with bromoferrocene by using palladium-catalyzed Suzuki-Miyaura crosscoupling conditions to give the intermediates $\mathbf{5 a}$ and $\mathbf{5 b}$ 

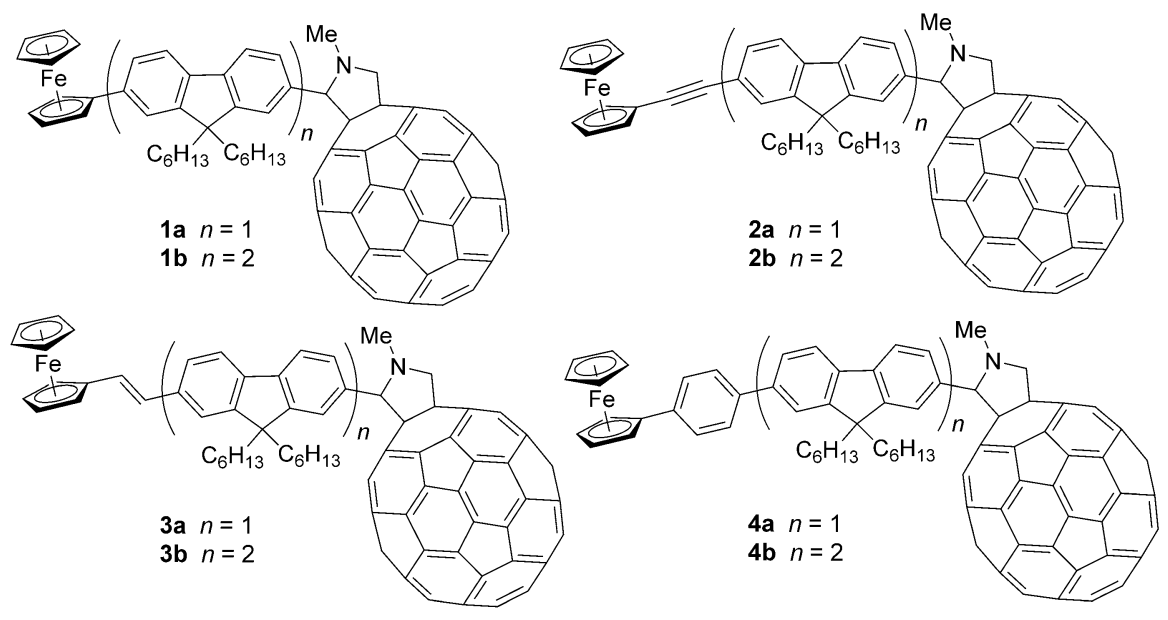

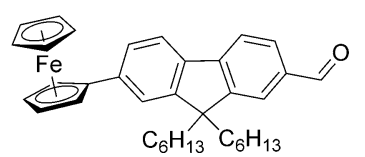

$5 a$

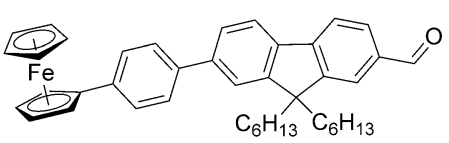

$8 \mathrm{a}$

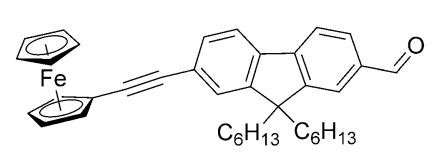

$6 \mathbf{a}$

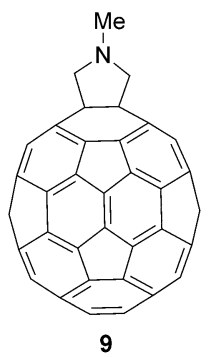

$7 a$

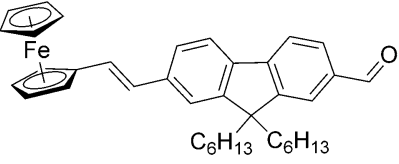

The synthesis of the phenylene-linked systems $\mathbf{4 a}$ and $\mathbf{4 b}$ is shown in Scheme 3. The fluorenyl units were functionalized with phenyl linkers to give $\mathbf{1 4}$ a,b before coupling with bromoferrocene to give precursors $\mathbf{8 a}, \mathbf{b}$. The structures of all the new compounds were assigned unambiguously based on their ${ }^{1} \mathrm{H}$ and ${ }^{13} \mathrm{C}$ NMR spectra and mass spectrometry.

Solution electrochemical studies: The redox properties of the $\mathrm{D}-\mathrm{B}-\mathrm{A}$ conjugates and the references were studied by cyclic voltammetry (CV). The measurements were performed at room temperature in a solvent mixture of $o$-dichlorobenzene/ acetonitrile $(4: 1 \quad \mathrm{v} / \mathrm{v}) \quad$ with $\mathrm{Bu}_{4} \mathrm{NClO}_{4}$ as the supporting electrolyte. Table 1 summarizes the relevant electrochemical data. Figure 2 shows the CVs of the monofluorene derivatives 1a-4a on both oxidative and reductive scans.

Each of the D-B-A compounds shows both oxidation
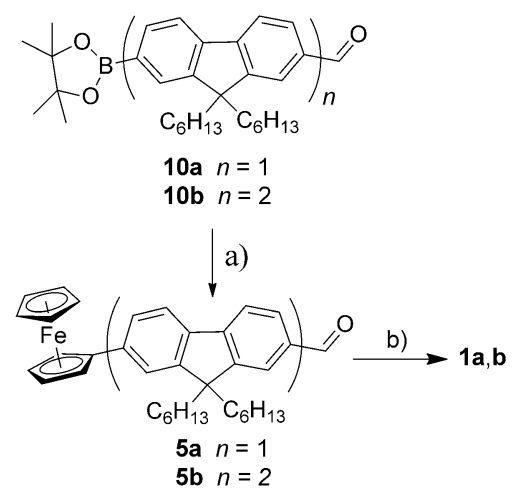

Scheme 1. Reagents and conditions: a) bromoferrocene, $\operatorname{Pd}(\mathrm{OAc})_{2}$, $\left.\mathrm{K}_{2} \mathrm{CO}_{3}, \mathrm{EtOH} / \mathrm{H}_{2} \mathrm{O}, 20^{\circ} \mathrm{C}, 49(\mathbf{5 a}) ; 29 \%(\mathbf{5 b}) ; \mathrm{b}\right) \mathrm{C}_{60}$, sarcosine, chlorobenzene, $130^{\circ} \mathrm{C}, 52(\mathbf{1 a}) ; 67 \%(\mathbf{1 b})$.

and, hence, compounds $\mathbf{1 a}$ and $\mathbf{1 b}$. Scheme 2 shows the synthesis of the analogous ethynyl-linked compounds $\mathbf{2} \mathbf{a}$ and 2b through the Sonogashira coupling of bromofluorene derivatives $11 \mathbf{a}$ and $11 \mathbf{b}$ to yield the intermediates $\mathbf{6 a}$ and $\mathbf{6 b}$. The vinyl-linked compounds $\mathbf{3 a}$ and $\mathbf{3 b}$ were synthesized similarly starting from 11a and $\mathbf{1 1} \mathbf{b}$ by using Heck conditions to give the intermediates $\mathbf{7 a}$ and $\mathbf{7 b}$.

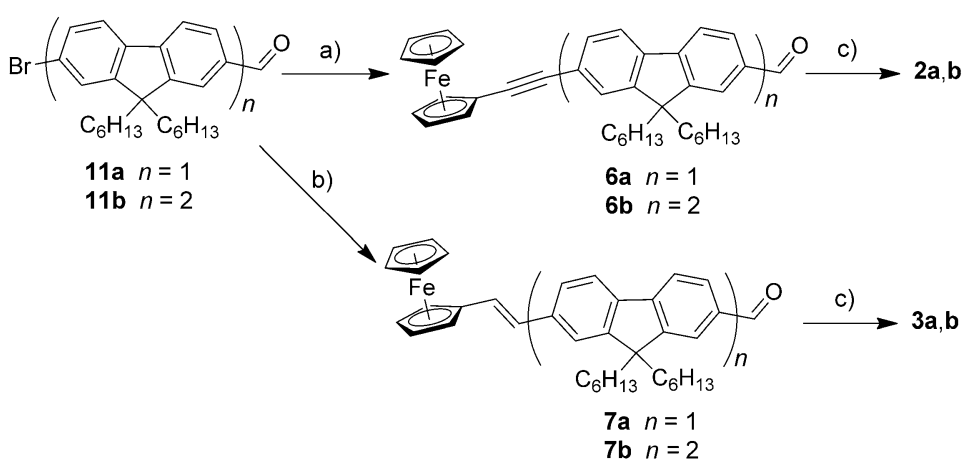

Scheme 2. Reagents and conditions: a) ethynylferrocene, $\operatorname{Pd}(\mathrm{OAc})_{2}$, $\mathrm{PPh}_{3}, \mathrm{CuI}, i \mathrm{Pr}_{2} \mathrm{NH}, 80^{\circ} \mathrm{C}, 78$ (6a); 23 (6b) 62 (7a), $67 \%$ (7b); b) vinylferrocene, $\mathrm{K}_{2} \mathrm{CO}_{3}, \mathrm{Bu}_{4} \mathrm{NBr}, \mathrm{Pd}(\mathrm{OAc})_{2} \mathrm{DMF}, 95^{\circ} \mathrm{C}, 62$ (7a); $67 \%$ (7b); c) $\mathrm{C}_{60}$, sarcosine, chlorobenzene, $130{ }^{\circ} \mathrm{C}, 64$ (2a); 56 (2b), 55 (3a), $48 \%$ (3b).

and reduction waves in the CV (Figure 2). The bifluorene analogues $\mathbf{1 b}-\mathbf{4 b}$ all behave in the same way. Oxidative scans (Figure $2 \mathrm{a}$ ) show quasi-reversible first oxidation potentials that can be assigned to the one-electron oxidation of Fc. Scanning further to $2000 \mathrm{mV}$ reveals an additional irreversible process ascribed to fluorene oxidation in the region between 1500 and $2000 \mathrm{mV}$. Some trends are apparent 

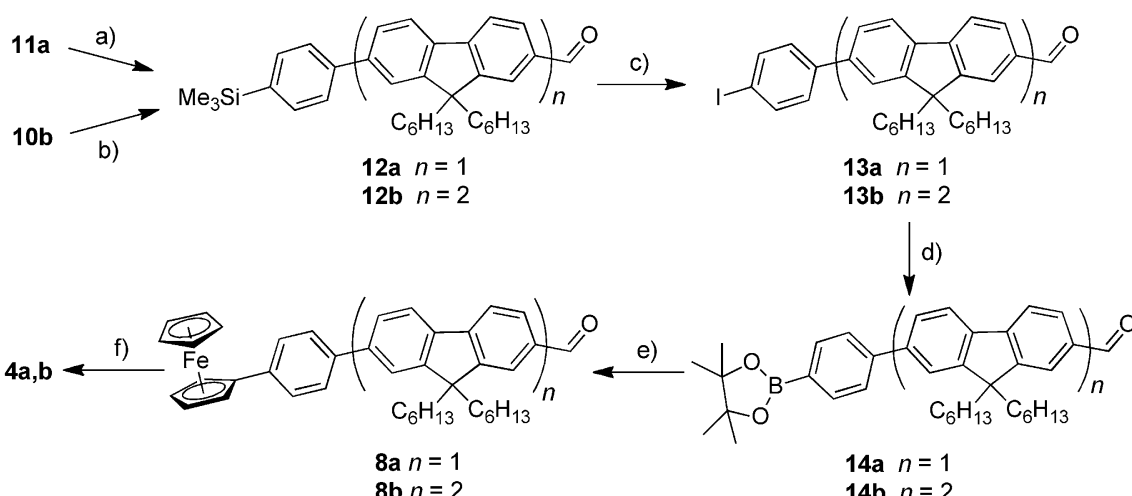

$8 \mathbf{b} n=2$

Scheme 3. Reagents and conditions: a) trimethyl[4-(4,4,5,5,-tetramethyl-1,3,2-dioxaborolan-2-yl)phenyl], Pd$\left(\mathrm{PPh}_{3}\right)_{4}, \mathrm{~K}_{2} \mathrm{CO}_{3}, 1,4$-dioxane, $85^{\circ} \mathrm{C}, 84 \%$ (12a); b) (4-bromophenyl)trimethylsilane, $\mathrm{Pd}\left(\mathrm{PPh}_{3}\right)_{4}, \mathrm{~K}_{2} \mathrm{CO}_{3}$, toluene, $110^{\circ} \mathrm{C}, 87 \%(\mathbf{1 2 b}) ;$ c) $\mathrm{ICl}, \mathrm{CH}_{2} \mathrm{Cl}_{2}, 0^{\circ} \mathrm{C}$ to $20^{\circ} \mathrm{C}, 90(\mathbf{1 3 a}) ; 96 \%$ (13b); d) $\mathrm{B}_{2} \mathrm{pin}_{2}, \mathrm{KOAc}, \mathrm{Pd}(\mathrm{OAc})_{2}, \mathrm{DMF}$ $90^{\circ} \mathrm{C}, 60$ (14a); $66 \%$ (14b); e) bromoferrocene, $\mathrm{Pd}(\mathrm{OAc})_{2}, \mathrm{~K}_{2} \mathrm{CO}_{3}, \mathrm{EtOH} / \mathrm{H}_{2} \mathrm{O}, 20^{\circ} \mathrm{C}, 37(\mathbf{8 a}) ; 28 \%(\mathbf{8 b})$; f) $\mathrm{C}_{60}$, sarcosine, chlorobenzene, $130{ }^{\circ} \mathrm{C}, 68(\mathbf{4 a}) ; 56 \%(\mathbf{4 b})$.

Table 1. Electrochemical data. ${ }^{[a]}$

\begin{tabular}{|c|c|c|c|c|c|c|}
\hline Compound & $E_{1 / 2, \text { red }}^{1}$ & $E_{1 / 2 \text {, red }}^{2}$ & $E_{1 / 2 \text {, red }}^{3}$ & $E_{1 / 2, \text { red }}^{4}$ & $E_{1 / 2, \mathrm{ox}}^{1}$ & $E_{\mathrm{ox}}^{2[\mathrm{~b}]}$ \\
\hline $\mathrm{C}_{60}$ & -803 & -1207 & -1673 & 2138 & - & - \\
\hline 9 & -920 & -1322 & -1873 & - & - & - \\
\hline $\mathbf{1 a}\left(\mathrm{Fc}-\mathrm{FL}-\mathrm{C}_{60}\right)$ & -915 & -1335 & -1886 & - & 209 & 1550 \\
\hline $\mathbf{1 b}\left(\mathrm{Fc}-\mathrm{FL}_{2}-\mathrm{C}_{60}\right)$ & -918 & -1335 & -1887 & - & 203 & 1556 \\
\hline $\mathbf{2} \mathbf{a}\left(\mathrm{Fc}-\mathrm{yne}-\mathrm{FL}-\mathrm{C}_{60}\right)$ & -909 & -1325 & -1881 & - & 314 & 1456 \\
\hline $2 \mathbf{b}\left(\mathrm{Fc}-\mathrm{yne}-\mathrm{FL}_{2}-\mathrm{C}_{60}\right)$ & -885 & -1297 & -1844 & - & 308 & 1462 \\
\hline $3 \mathbf{a}\left(\mathrm{Fc}-\mathrm{C}=\mathrm{C}-\mathrm{FL}-\mathrm{C}_{60}\right)$ & -913 & -1330 & -1879 & - & 178 & 1466 \\
\hline $3 \mathbf{b}\left(\mathrm{Fc}-\mathrm{C}=\mathrm{C}-\mathrm{FL}_{2}-\mathrm{C}_{60}\right)$ & -910 & -1330 & -1878 & - & 173 & 1462 \\
\hline $\mathbf{4 a}\left(\mathrm{Fc}-\mathrm{Ph}-\mathrm{FL}-\mathrm{C}_{60}\right)$ & -915 & -1333 & -1888 & - & 233 & 1641 \\
\hline $4 \mathbf{b}\left(\mathrm{Fc}-\mathrm{Ph}-\mathrm{FL}_{2}-\mathrm{C}_{60}\right)$ & -918 & -1332 & -1887 & - & 218 & 1585 \\
\hline $\mathrm{Fc}$ & - & - & - & - & 197 & - \\
\hline $5 \mathbf{a}(\mathrm{Fc}-\mathrm{FL}-\mathrm{CHO})$ & $-2101^{[\mathrm{c}]}$ & - & - & - & 227 & - \\
\hline $5 \mathbf{b}\left(\mathrm{Fc}-\mathrm{FL}_{2}-\mathrm{CHO}\right)$ & $-2078^{[\mathrm{c}]}$ & - & - & - & 219 & - \\
\hline 6a (Fc-yne-FL-CHO) & $-1960^{[\mathrm{c}]}$ & - & - & - & 320 & - \\
\hline $6 \mathbf{b}\left(\mathrm{Fc}-\mathrm{yne}-\mathrm{FL}_{2}-\mathrm{CHO}\right)$ & $-1950^{[\mathrm{c}]}$ & - & - & - & 315 & - \\
\hline $7 \mathbf{a}(\mathrm{Fc}-\mathrm{C}=\mathrm{C}-\mathrm{FL}-\mathrm{CHO})$ & $-2010^{[\mathrm{c}]}$ & - & - & - & 189 & - \\
\hline 7b $\left(\mathrm{Fc}-\mathrm{C}=\mathrm{C}-\mathrm{FL}_{2}-\mathrm{CHO}\right)$ & $-2011^{[\mathrm{c}]}$ & - & - & - & 181 & - \\
\hline $8 \mathbf{a}(\mathrm{Fc}-\mathrm{Ph}-\mathrm{FL}-\mathrm{CHO})$ & $-2072^{[\mathrm{c}]}$ & - & - & - & 230 & - \\
\hline $8 \mathbf{b}\left(\mathrm{Fc}-\mathrm{Ph}-\mathrm{FL}_{2}-\mathrm{CHO}\right)$ & $-2071^{[\mathrm{c}]}$ & - & - & - & 216 & - \\
\hline
\end{tabular}

[a] Potentials in $\mathrm{mV}$ (half-wave potentials: $E_{1 / 2}$ ); scan rate $100 \mathrm{mV} \mathrm{s}^{-1}$; glassy carbon working electrode; $\mathrm{Ag} / \mathrm{AgNO}_{3}$ reference electrode; Pt-wire counter electrode; $0.1 \mathrm{~m}$ $\mathrm{Bu}_{4} \mathrm{NClO}_{4}$ in $o-\mathrm{DCB} / \mathrm{CH}_{3} \mathrm{CN}(4: 1 \mathrm{v} / \mathrm{v}) ; 20^{\circ} \mathrm{C}$. [b] Broad, irreversible oxidation wave. [c] Broad, irreversible reduction wave.

within the series. For compounds, in which $\mathrm{Fc}$ is either linked directly to FL or through a phenylene spacer $(\mathbf{1} \mathbf{a}, \mathbf{1 b}$, 4a, and $4 \mathbf{b}$ ), the first oxidation step shows small cathodic shifts of $12,6,36$, and $21 \mathrm{mV}$, respectively, relative to $\mathrm{Fc}$. This slight increase in the oxidation potentials is caused by the permanent dipole moments of the molecules, which makes the molecular ensemble more difficult to oxidize. Compounds $\mathbf{3 a}$ and $\mathbf{3 b}$, which have a vinyl spacer, show a small decrease in oxidation potential by 9 and $14 \mathrm{mV}$ compared with Fc. This suggests that the bridge in $\mathbf{3} \mathbf{a}$ and $\mathbf{3 b}$ is able to donate electrons in addition to the Fc. Hence, the communication between the donor and acceptor in these systems is enhanced by the bridge. This result agrees with the work of Wielopolski et al., in which an exTTF donor was linked to $\mathrm{C}_{60}$ by using an oligo-vinylfluorene bridge. ${ }^{[22]}$ d)

$14 \mathrm{~b} n=2$

Incorporating a vinyl spacer between the exTTF unit and the FL bridge decreased the electronic repulsion between the two electron-rich systems, allowing the bridge to adopt a more planar structure and, thus, providing a continuous $\pi$-electron pathway from the donor across the vinylfluorene bridge to the $\mathrm{C}_{60}$ acceptor.

Conversely, compounds $\mathbf{2 a}$ and $\mathbf{2} \mathbf{b}$, which have an alkynyl spacer, show an increase in oxidation potential of 117 and $111 \mathrm{mV}$, respectively, compared with both $\mathrm{Fc}$ and all the other compounds, implying significantly reduced donor abilities of $\mathbf{2} \mathbf{a}$ and $\mathbf{2} \mathbf{b}$, which can be ascribed to the electron-accepting alkyne unit. This is a similar shift to that observed when an alkyne group is linked to the electron-donating TTF. ${ }^{[8 c]}$

In the reduction scans, each of the $\mathrm{D}-\mathrm{B}-\mathrm{A}$ compounds shows three consecutive reversible one-electron reduction waves that are assigned clearly to the fulleropyrrolidine moiety by comparison with $\mathrm{C}_{60}$ and 9. Their potentials are very similar to those of 9, indicating that electronic interactions in the ground state are small. Predictably, these reduction waves are absent in the formyl precursor compounds (Table 1), for which a broad irreversible reduction wave arising from the substituted fluorenyl moiety is observed at approximately $-2.0 \mathrm{~V}$.

Molecular modeling: Geometry optimizations of 1 4 (with methyl groups replacing hexyl) were performed at the density functional theory (DFT) level by using the unrestricted Hartree-Fock method with the M062X hybrid meta functional ${ }^{[26]}$ and the LANL2DZ ${ }^{[27]}$ valence basis set with Stuttgart/Dresden effective core potentials ${ }^{[28]}$ for iron combined with $6-31 \mathrm{G}^{*[29]}$ for carbon, nitrogen, and hydrogen. All computations were performed with the Gaussian 09 suite of programs. $^{[30]}$

The optimized geometries are shown in Figure 3 including the dihedral angles between oFL planes among and between oFL and the cyclopentadienyl rings of the Fc moieties. Comparing the structures shows that the dihedral angle between the two FLs is $(40 \pm 1)^{\circ}$ in all bifluorene-containing conjugates $(\mathbf{1 b}, \mathbf{2 b}, \mathbf{3 b}$, and $\mathbf{4 b})$. This conformation represents a compromise between the steric hindrance of the ortho-hydrogen atoms and the maximum overlap of $\pi$-orbitals. Figure 3 shows that the linkage between Fc and the oFLs is responsible for the largest structural variations within the four different systems. This is particularly evident in the monofluorene-based conjugates (1a, $\mathbf{2 a}, \mathbf{3 a}$, and $\mathbf{4 a})$. This 

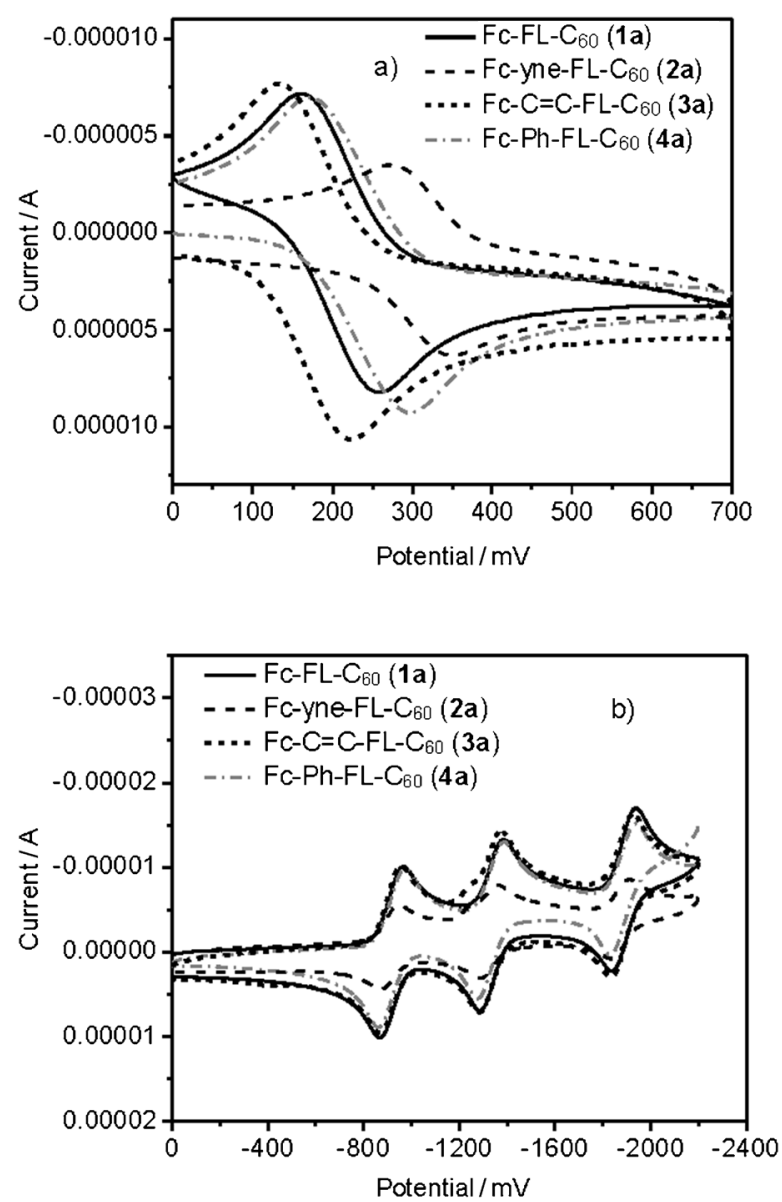

Figure 2. CVs of monofluorene derivatives $\mathbf{1 a}-\mathbf{4 a}$ in $o-\mathrm{DCB} / \mathrm{CH}_{3} \mathrm{CN}(4: 1$ $\mathrm{v} / \mathrm{v}$ ): a) oxidative scans between 0 and $+700 \mathrm{mV}$; b) reductive scans between 0 and $-2400 \mathrm{mV}$ (for conditions see Table 1 ).

must affect the overlap between the $\pi$-orbitals of $\mathrm{Fc}$ and oFL and, as such, impact the overall $\pi$-conjugated pathway between $\mathrm{Fc}, \mathrm{oFL}$, and $\mathrm{C}_{60}$. Importantly, the insertion of an ethynyl or vinylene spacer, as in $\mathbf{2} \mathbf{a}$ and $\mathbf{3 a}$ a, reduces the electrostatic repulsion between the cyclopentadienyl and the oFLs and favors planarity between the adjacent FLs and Fc. On the contrary, the phenyl spacer in $\mathbf{4 a}$ induces a torsion of more than $30^{\circ}$ between the cyclopentadienyl ring and the adjacent FL. In the difluorene systems $(\mathbf{1 b}, \mathbf{2 b}, \mathbf{3 b}$, and $\mathbf{4 b})$ the electrostatic repulsion between the FLs dominates the configuration. Nevertheless, an almost planar structure is found for $\mathbf{2} \mathbf{b}$ due to the ethyne linker.

The HOMO and LUMO energies are summarized in Table 2. The LUMO energies are constant within a tenth of a volt and the HOMO energies only vary in a narrow range (from -6.4 to $-6.7 \mathrm{eV}$ ). These results are consistent with little mutual influence of the donor and acceptor moieties through the bridge. In particular, the LUMO energies are unperturbed compared with $\mathrm{C}_{60}$.

Examining the orbitals (Figure S1, the Supporting Information) reveals the donor-acceptor chemical architecture of the systems. The LUMO is always located on $\mathrm{C}_{60}$, whereas the HOMO is homogenously distributed over the entire bridge and shows significant overlap with the Fc units. As expected, the cyclopentadienyl $\pi$-system provides the electronic communication between $\mathrm{Fc}$ and the oFL bridges. In this regard, the overlap between the $\pi$-orbitals of the two moieties will be crucial for charge injection into the oFL spacer. Furthermore, the $\pi$-orbitals of the oFLs strongly contribute to the HOMOs. This results from the close energy-matching between the Fcs and the oFLs and allows strong electronic-coupling. Hence, charge transfer may easily occur upon exciting either the oFLs or the Fcs. Inspection of the lower-energy molecular orbitals indicates two additional aspects. Firstly, the lower MOs show significant contributions from $\mathrm{C}_{60}$, which could result in charge transfer. However, there is a significant energy gap between HOMO and HOMO-1 in all systems (Table 2). On this basis, we rule out the occurrence of charge transfer in solution, in which solvent stabilization effects will lead to a further increase of the energy gap. Moreover, HOMO-2 and HOMO-4 nicely corroborate the effects of the elongation of the oFLs. As seen from the distribution of the electron densities, upon elongation the HOMO-2 and HOMO-4 show increased contributions to the electronic coupling between the Fcs and $\mathrm{C}_{60} \mathrm{~s}$.

Photophysics: The electronic interactions in the excited state were studied by means of photophysical methods. A comparison of the ground state absorption spectra of the references (5a-8a and 9) and the electron-donor-acceptor conjugates (1-4) in toluene and THF revealed absorptions of the individual building blocks (Figure 4). No spectroscopic evidence for any aggregation was noted for the investigated references/conjugates in the concentration range of the photophyscial experiments, that is, $10^{-6} \mathrm{M}$. In the UV spectra, $\mathrm{C}_{60}$ transitions are discernable at 280 and $329 \mathrm{~nm}$. Fc absorptions $(338 \mathrm{~nm})$ are masked by the broad features of the oFLs. References 5a-8a show only slight dependence on the linkage between Fc and oFL, except for 7a. Apparently, the vinylene unit in $\mathbf{7 a}$ contributes for the most part to the extension of the $\pi$-system of the oFLs. This situation changes when going to 1-4. For example, upon increasing the bridge length, the maxima shift in THF from $328 \mathrm{~nm}$ for 1a to $350 \mathrm{~nm}$ for $\mathbf{3 b}$. At $450 \mathrm{~nm}$, the Fc absorption is discernable in the form of a broad shoulder. Notably, a comparison between $\mathbf{1} \mathbf{a}, \mathbf{b}$ and $\mathbf{4 a}, \mathbf{b}$ reveals the same positions of the absorption maxima. This is in line with the molecular modeling studies, in which the phenyl units and the adjacent FLs confine a dihedral angle of 31.7 and $35.2^{\circ}$ for $\mathbf{4 a}$ and $\mathbf{4 b}$, respectively. Hence, this out-of-plane torsion hampers the $\pi$-conjugation and, in turn, the extension of the $\pi$ system. On the other hand, the insertion of an ethyne linker, which promotes a more planar configuration between the Fc cyclopentadienyl and the adjacent oFLs, leads to a slight extension of the $\pi$-conjugation. As seen for references $5 \mathbf{a}-8 \mathbf{a}$, the most significant extension arises from the vinylene linkage in $\mathbf{3}$.

The fluorescence assays were performed at $375 \mathrm{~nm}$ excitation. This wavelength was chosen to excite mainly the oFL 
Ia

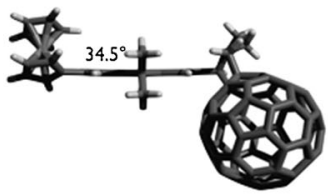

$2 \mathbf{a}$

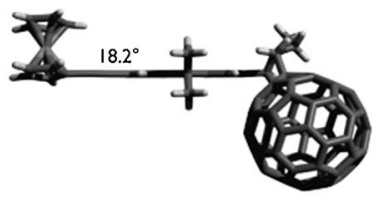

$3 \mathbf{a}$

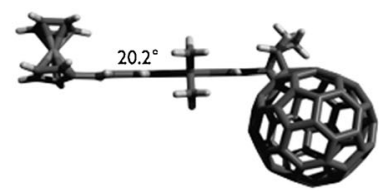

$4 a$

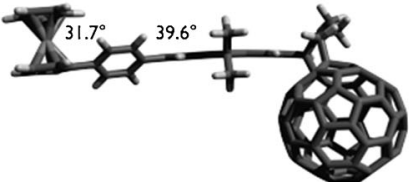

I b

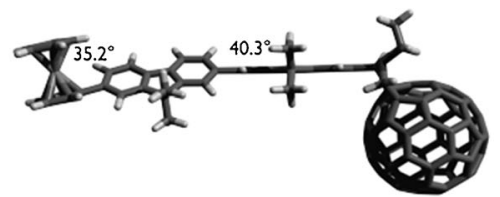

$\mathbf{2 b}$

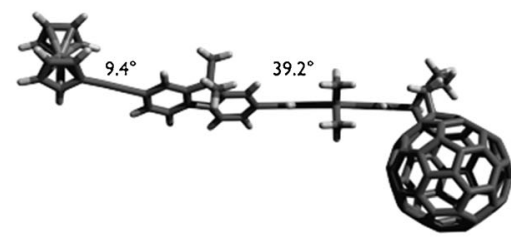

3b

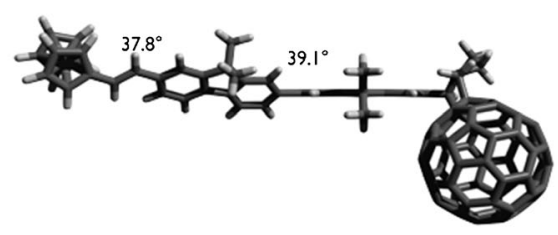

$4 b$

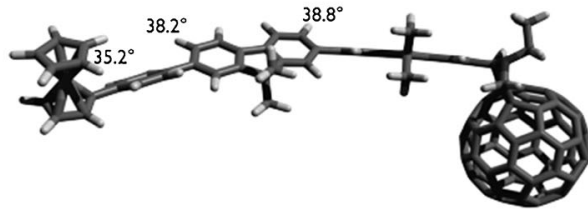

Figure 3. M062X/(6-31G*+LANL2DZ) geometries with the corresponding dihedral angles depicted and stated below in parenthesis. In $\mathbf{1} \mathbf{a}, \mathbf{2} \mathbf{a}$, and $\mathbf{3} \mathbf{a}$, the angles are determined between the Fc cyclopentadienyl plane and the FL plane $\left(34.5,18.2\right.$, and $20.2^{\circ}$, respectively) and in $\mathbf{4 a}$ between the Fc cyclopentadienyl plane and the phenyl ring $\left(31.7^{\circ}\right)$ and the phenyl ring and the FL plane $\left(39.6^{\circ}\right)$. In $\mathbf{1 b}, \mathbf{2 b}$, and $\mathbf{3 b}$, the angles are determined between the Fc cyclopentadienyl plane and the adjacent FL plane (35.2, 9.4, and $37.8^{\circ}$, respectively) and between the two FL planes (40.3, 39.2, and $39.1^{\circ}$, respectively). In $\mathbf{4 b}$, the angles are determined between the $\mathrm{Fc}$ cyclopentadienyl plane and the phenyl ring $\left(35.2^{\circ}\right)$, the phenyl ring and the adjacent FL plane $\left(38.2^{\circ}\right)$ and between two FL planes $\left(38.8^{\circ}\right)$.

Table 2. M062X/(6-31G*+LANL2DZ) calculated energy levels $[\mathrm{eV}]$ of the frontier orbitals for 1-4.

\begin{tabular}{lllllllll}
\hline Orbital & $\mathbf{1 a}$ & $\mathbf{1 b}$ & $\mathbf{2 a}$ & $\mathbf{2 b}$ & $\mathbf{3 a}$ & $\mathbf{3 b}$ & $\mathbf{4 a}$ & $\mathbf{4 b}$ \\
\hline LUMO & -2.6 & -2.6 & -2.6 & -2.6 & -2.6 & -2.6 & -2.6 & -2.6 \\
HOMO & -6.7 & -6.5 & -6.6 & -6.5 & -6.5 & -6.4 & -6.7 & -6.5 \\
HOMO-1 & -6.8 & -6.8 & -6.9 & -6.9 & -6.9 & -6.8 & -6.8 & -6.8 \\
HOMO-2 & -7.0 & -7.0 & -7.0 & -7.0 & -7.0 & -7.0 & -7.0 & -7.0 \\
HOMO-3 & -7.0 & -7.0 & -7.1 & -7.1 & -7.0 & -7.0 & -7.0 & -7.0 \\
HOMO-4 & -7.1 & -7.1 & -7.1 & -7.1 & -7.1 & -7.1 & -7.1 & -7.1 \\
\hline
\end{tabular}

units. The fluorescence spectra are divided into two regions: the region between 410 and $600 \mathrm{~nm}$ and the region between 680 and $800 \mathrm{~nm}$. As seen in the fluorescence spectra recorded with references $5 \mathbf{a}-\mathbf{8} \mathbf{a}$, the oFLs emit strongly in the 410 to $600 \mathrm{~nm}$ region (the upper part of Figure 5). In terms of fluorescence maxima the trend resembles that seen in absorption spectra, with the maxima shifting from 445 for 5 to $456 \mathrm{~nm}$ for 7. As seen from Figure S4 (in the Supporting Information), the oFL fluorescence is strongly quenched in the presence of $\mathrm{C}_{60}$ and $\mathrm{Fc}$, which points to a rapid excitedstate energy-transfer from the photoexcited oFLs to $\mathrm{C}_{60}$. Notably, the fluorescence quantum yields in oFLs are close to unity. Importantly, the oFL fluorescence is quenched in THF by a factor of 10 when comparing oFLs in the absence (5a8a) and in the presence of $\mathrm{C}_{60}$ (1-4; Figure S4 and Table S2, the Supporting Information), which points to augmented oFL excited-state deactivations in the latter cases. Here, the energy transfer from singlet excited oFLs to ground state $\mathrm{C}_{60}$ is operative (see below). The $\mathrm{C}_{60}$ fluorescence is located in the 680 to $800 \mathrm{~nm}$ region. Inspecting the $\mathrm{C}_{60}$ fluorescence features in the electron-donoracceptor conjugates 1-4 in relation to 9 provides the first insights into the excited-state deactivation (lower part of Figure 5). In 1-4, the $\mathrm{C}_{60}$ fluorescence is considerably quenched. At first glance, the quenching depends on the distance between the donors and the acceptors. Furthermore, the dependence on the $\pi$-conjugation length of the bridge resembles the trends of the absorption spectra. In other words, increasing the length of the bridge without changing the $\pi$ conjugation leads to weaker quenching of the $\mathrm{C}_{60}$ fluorescence. A closer look reveals that the quenching depends also on the solvent polarity, that is, increasing the polarity from toluene to THF and to benzonitrile increases the fluorescence quenching.

Complementary fluorescence measurements, in which 1-4 were excited in the range of dominant $\mathrm{C}_{60}$ absorption, that is, at $550 \mathrm{~nm}$, led to similar trends with quantum yields that ranged in THF from $1.14 \times 10^{-5}(\mathbf{1} \mathbf{a})$ to $3.75 \times 10^{-4}(\mathbf{2} \mathbf{b}$; Figure S2 and Table S1, the Supporting Information). Since solvents of higher polarity tend to assist in stabilizing radical-ion pairs more than solvents of lower polarity, and the quenching increases with decreasing electron-donor-acceptor separation, a rapid charge-transfer process as deactivation of the singlet-excited state is most probable (see below). The radical-ion-pair stabilization was corroborated by means of calculations of their respective energies (Table 3). In contrast, a deactivation by means of energy transfer to yield a Fc-centered excited state or by accelerated intersystem crossing is unlikely to play a dominant role. Both of the latter pathways should be solvent-polarity independent. The quantum yields for all systems in toluene, THF, and benzo- 

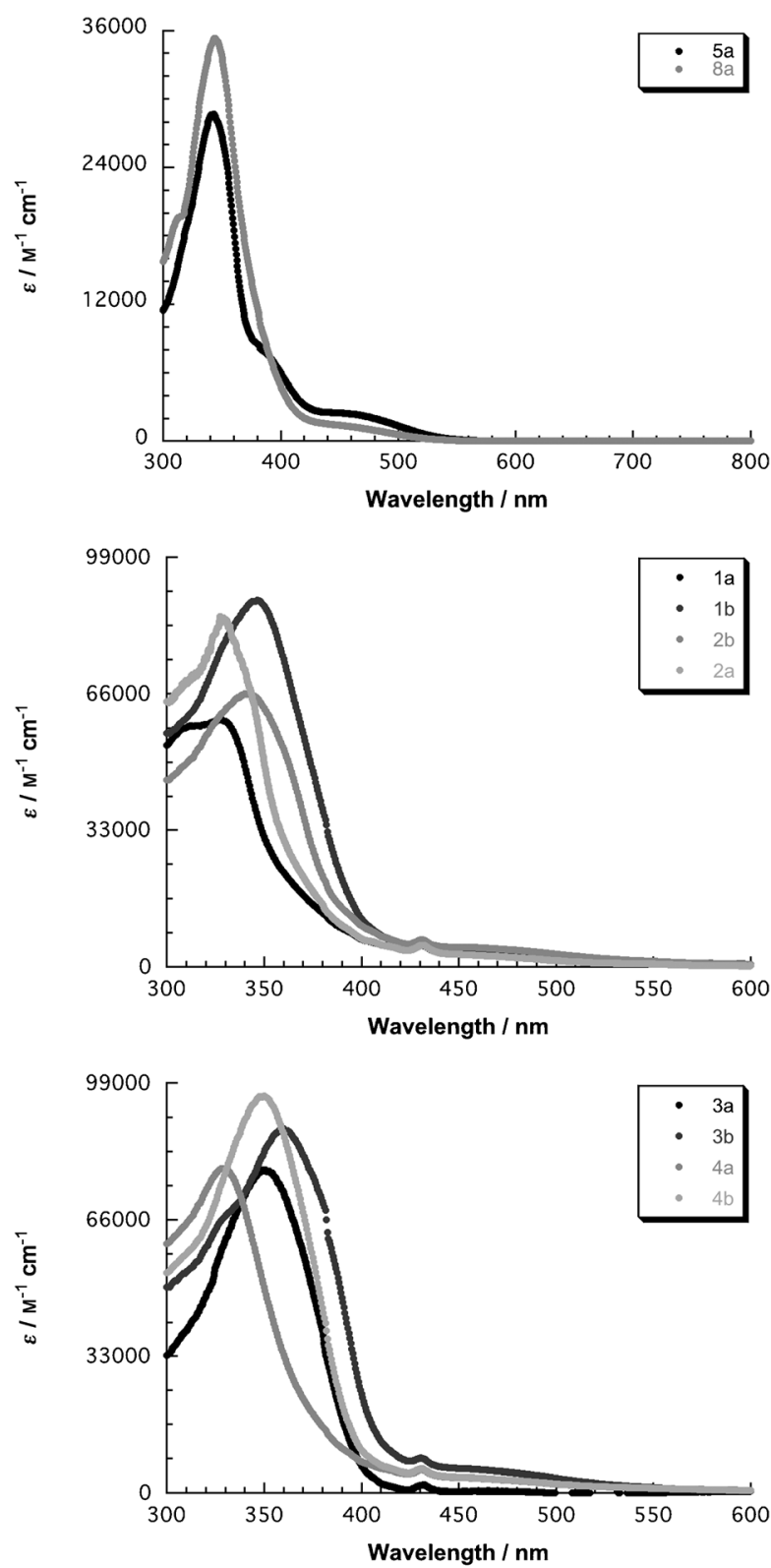

Figure 4. Upper part: absorption spectra of references $5 \mathbf{a}$ and $\mathbf{8 a}$. Central part: absorption spectra of electron-donor-acceptor conjugates $\mathbf{1 a}, \mathbf{1 b}$, $\mathbf{2 a}$, and $\mathbf{2} \mathbf{b}$ in THF at room temperature. Lower part: absorption spectra of electron-donor-acceptor conjugates $\mathbf{3 a}, \mathbf{3 b}, \mathbf{4 a}$, and $\mathbf{4 b}$ in THF at room temperature.

nitrile are listed in Table 3 . In corroboration of the oFLs to $\mathrm{C}_{60}$ energy-transfer postulate, we recorded excitation spectra that feature contributions from oFLs and $\mathrm{C}_{60}$ (Figure S3, the Supporting Information).

Conclusive evidence for a successful charge-transfer reaction comes from transient absorption measurements. An excitation wavelength of $387 \mathrm{~nm}$ was chosen to excite the oFLs in the references (5a-8a) and in the electron-donoracceptor conjugates (1-4). In all of the references $(5 \mathbf{a}-\mathbf{8} \mathbf{a})$ the formation of the oFL singlet excited states is seen featuring broad maxima in the 500 to $750 \mathrm{~nm}$ and in the 800 to
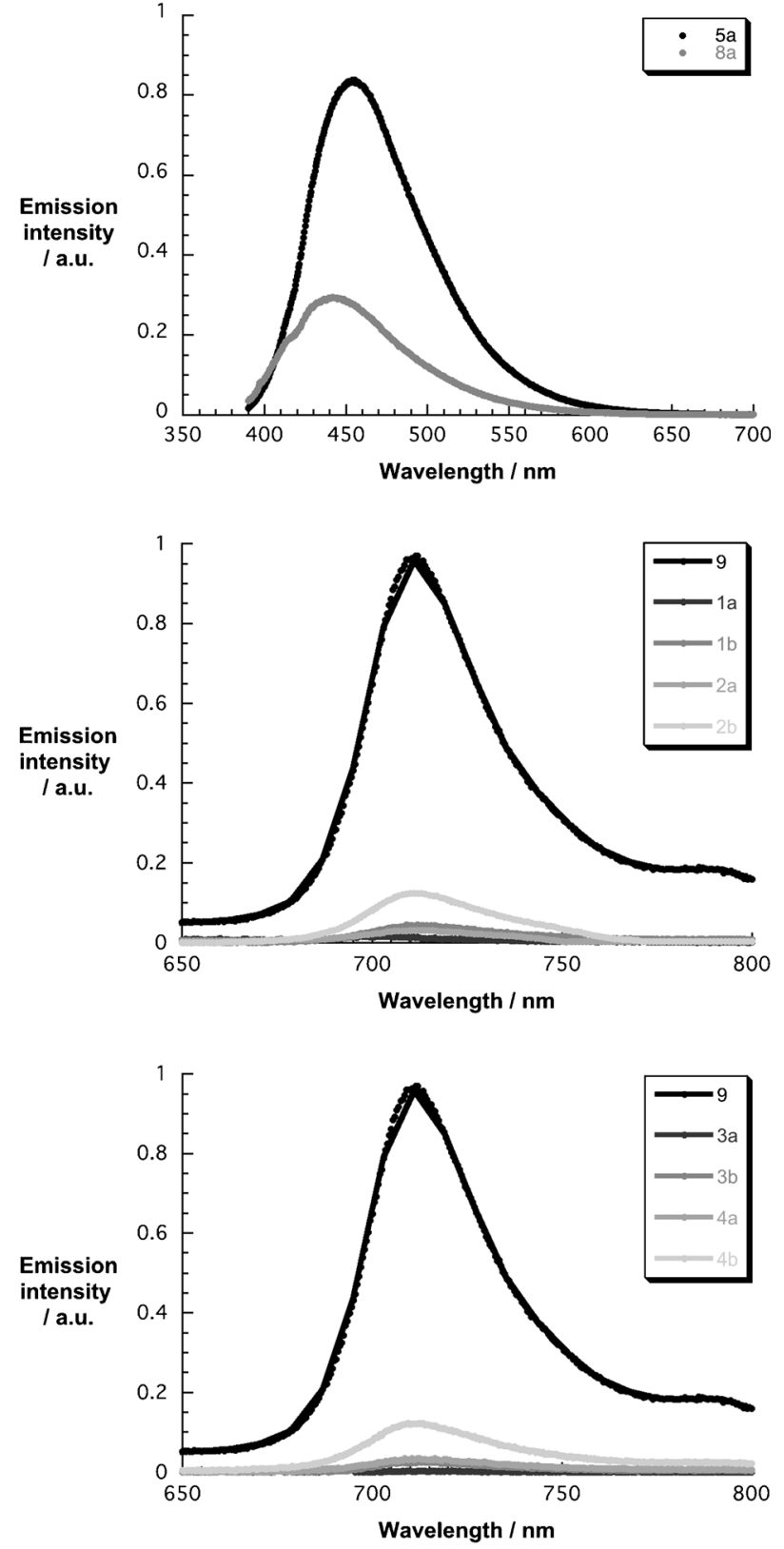

Figure 5. Upper part: fluorescence spectra of references 5a and 8a in THF, with matching absorption of 0.05 at the $375 \mathrm{~nm}$ excitation wavelength. Central part: fluorescence spectra of reference $\mathbf{9}$ and conjugates 1a, 1b, 2a, 2b in THF, with matching absorption of 0.05 at the $375 \mathrm{~nm}$ excitation wavelength. Lower part: fluorescence spectra of reference 9 and conjugates $\mathbf{3 a}, \mathbf{3 b}, \mathbf{4 a}, \mathbf{4 b}$ in THF, with matching absorption of 0.05 at the $375 \mathrm{~nm}$ excitation wavelength.

$1100 \mathrm{~nm}$ regions. An example for $\mathbf{8 a}$ in THF is shown in Figure 6. A closer look at the oFL singlet-excited-state formation suggests that a short-lived intermediate (a higherlying singlet-excited-state) is involved. In particular, maxima at $490 \mathrm{~nm}$ for $\mathbf{6 a}$, at $560 \mathrm{~nm}$ for $\mathbf{7 a}$, and at $530 \mathrm{~nm}$ for $\mathbf{8 a}$ evolve and reflect the trend in $\pi$-conjugation. These higherlying singlet excited features transform on a timescale of less than 1 ps into the corresponding oFL singlet signatures. The maxima redshift in accordance with the trends estab- 
Table 3. Photophysical data of $\mathrm{Fc}-\mathrm{oFL}-\mathrm{C}_{60}$ electron-donor-acceptor conjugates in solution at room temperature. ${ }^{[\mathrm{a}]}$

\begin{tabular}{|c|c|c|c|c|c|c|c|}
\hline & \multicolumn{3}{|c|}{$\mathrm{C}_{60}-\Phi_{\mathrm{FL}}$ with $\lambda_{\mathrm{exc}}=375 \mathrm{~nm}$} & \multicolumn{2}{|c|}{$\mathrm{C}_{60}-\tau_{\text {singlet }}[\mathrm{ps}]$} & \multicolumn{2}{|c|}{$\tau_{\mathrm{CR}}[\mathrm{ps}]$} \\
\hline & toluene & $\mathrm{THF}$ & $\mathrm{PhCN}$ & THF & $\mathrm{PhCN}$ & THF & $\mathrm{PhCN}$ \\
\hline$\overline{1 a}$ & $1.2 \times 10^{-5}$ & $1.9 \times 10^{-6}$ & $9.1 \times 10^{-7}$ & $<1$ & $<1$ & 28 & 34 \\
\hline $\mathbf{1 b}$ & $1.6 \times 10^{-4}$ & $3.6 \times 10^{-5}$ & $2.0 \times 10^{-5}$ & 34 & 30 & 485 & 572 \\
\hline $2 \mathbf{a}$ & $1.6 \times 10^{-4}$ & $4.3 \times 10^{-5}$ & $1.5 \times 10^{-5}$ & 42 & 46 & 154 & 134 \\
\hline $2 \mathbf{b}$ & $2.9 \times 10^{-4}$ & $2.0 \times 10^{-4}$ & $1.0 \times 10^{-4}$ & 31 & 38 & 1382 & 2114 \\
\hline $3 \mathbf{a}$ & $1.5 \times 10^{-5}$ & $5.8 \times 10^{-6}$ & $8.8 \times 10^{-7}$ & 2.1 & $<1$ & 27 & 33 \\
\hline 3b & $9.9 \times 10^{-5}$ & $1.6 \times 10^{-5}$ & $9.8 \times 10^{-6}$ & 21 & 31 & 728 & 823 \\
\hline $4 \mathbf{a}$ & $1.3 \times 10^{-4}$ & $3.3 \times 10^{-5}$ & $1.5 \times 10^{-5}$ & 9.5 & 31 & 164 & 189 \\
\hline $4 b$ & $1.9 \times 10^{-4}$ & $8.7 \times 10^{-5}$ & $6.3 \times 10^{-5}$ & $-^{[\mathrm{b}]}$ & $-^{[\mathrm{b}]}$ & 2077 & 2278 \\
\hline \multicolumn{8}{|c|}{$\mathrm{oFL}-\Phi_{\mathrm{FL}}$ with $\lambda_{\mathrm{exc}}=350 \mathrm{~nm}$} \\
\hline $1 \mathrm{a}$ & & 0.0025 & & & & & \\
\hline $3 \mathbf{a}$ & & 0.0022 & & & & & \\
\hline $5 \mathbf{a}$ & & 0.013 & & & & & \\
\hline $6 a$ & & $3.4 \times 10$ & & & & & \\
\hline $6 \mathrm{~b}$ & & 0.042 & & & & & \\
\hline $7 \mathbf{a}$ & & 0.038 & & & & & \\
\hline $7 \mathrm{~b}$ & & 0.13 & & & & & \\
\hline $8 \mathbf{a}$ & & 0.0097 & & & & & \\
\hline
\end{tabular}

[a] $\Phi_{\mathrm{FL}}: \mathrm{C}_{60}$ and oFL fluorescence quantum yields; $\tau_{\text {singlet }}: \mathrm{C}_{60}$ singlet-excited-state lifetimes in picoseconds as determined by femtosecond transient absorption studies; $\tau_{\mathrm{CR}}: \mathrm{C}_{60}{ }^{-} / \mathrm{Fc}^{*+}$ radical-ion-pair-state lifetimes as determined by femtosecond transient absorption studies. [b] Cannot be fit.
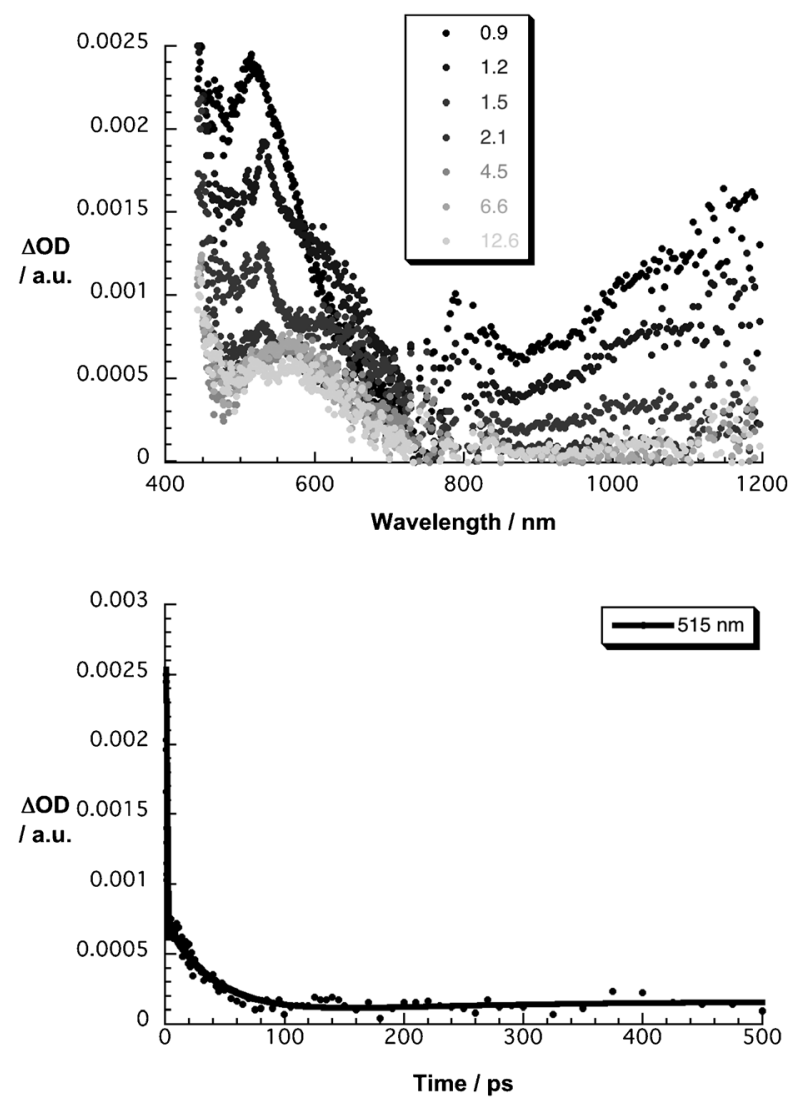

Figure 6. Upper part: differential absorption spectra (visible and near-infrared) obtained upon femtosecond flash photolysis $(387 \mathrm{~nm}, 100 \mathrm{~nJ})$ of $8 \mathbf{a}$ in argon-saturated THF with time delays between 0.9 and $12.6 \mathrm{ps}$ at room temperature. Lower part: absorption-time profile at $515 \mathrm{~nm}$ monitoring the excited-state decay. lished in the absorption spectra, for example, from 560 for 5a to $660 \mathrm{~nm}$ for 7a. The oFL singlet excited-state features decay, due the presence of the deactivating ferrocene, quickly within tens of picoseconds (Table 3). As far as the identity of the products is concerned, please note the lack of spectroscopic fingerprints for either the one-electron oxidized ferrocene $\left(\mathrm{Fc}^{++}\right)$or the one-electron reduced oFLs $\left(\mathrm{oFLs}^{--}\right)$. In light of the aforementioned, we conclude that either an energy transfer to an energetically lower-lying and spectroscopically weakly absorbing Fc triplet excited-state or, alternatively, a simple heavy atom affect (see below) dictates the oFL singlet excited-state deactivation.

The situation clearly changes when inspecting the electron-donor-acceptor conjugates 1-4 upon $387 \mathrm{~nm}$ photoexcitation. Immediately upon excitation two bands arise in the differential absorption spectra. In particular, one band covers the 400 to $500 \mathrm{~nm}$ range, whereas another band dominates the 800 to $1100 \mathrm{~nm}$ range. Notably, the transient resembles the characteristics of the $\mathrm{C}_{60}$ singlet excited-state. In principle, two different scenarios might be anticipated (Scheme 4). Firstly, direct excitation into the oFLs to yield their singlet excited-states followed by a rapid transduction of the singlet-excited-state energy to the lower-lying $\mathrm{C}_{60}$ singlet excited state. The actual energy-transfer occurs on a faster timescale than the resolution of our experimental setup. This further confirms the stronger oFL fluorescence quenching when $\mathrm{C}_{60}$ is present. Secondly, laser excitation directly powers the $\mathrm{C}_{60}$ singlet excited-state population. In fact, the light participation of $\mathbf{1 - 4}$ at the $387 \mathrm{~nm}$ excitation wavelength suggests relative distributions of 1.2 to 1.0 between the first and second scenario. The deactivation of the $\mathrm{C}_{60}$ singlet excited-states occurs within a time frame of up to 30 ps. Such a singlet deactivation is in line with the distinct quenching seen in the fluorescence experiments (upper part of Figure 5). Table 3 lists all of the singlet-excited-state lifetimes.

The singlet-excited-state deactivation is kinetically and spectroscopically linked to another process. In all of the electron-donor-acceptor conjugates, the formation of the one-electron reduced $\mathrm{C}_{60}\left(\mathrm{C}_{60}{ }^{--}\right)$with its spectral signature around $1010 \mathrm{~nm}$ evolves in the near-infrared part of the spectrum (Figure 7, the Supporting Information, S5-S11). In parallel, the visible part of the spectrum gives rise to the development of maxima at around 500 and $680 \mathrm{~nm}$. The former resembles an additional feature of the one-electron reduced $\mathrm{C}_{60}$, whereas the latter is probably a mixture of $\mathrm{Fc}^{+}$ and $\mathrm{oFL}^{+}$according to the HOMO distribution (the Supporting Information, Figure S1). As such, we infer that the charge-transfer yields $\mathrm{C}_{60}{ }^{-} / \mathrm{Fc}^{*+}$ radical-ion-pair states in 14. Further support for this notion was obtained from a thermodynamic consideration of the underlying driving forces to form $\mathrm{C}_{60}{ }^{-} / \mathrm{Fc}^{\cdot+}(1.15 \pm 0.07 \mathrm{eV})$. Please note the sound agreement between the values listed in Table 3 and the different $\mathrm{C}_{60}$ singlet-excited-state lifetimes, on one hand, and the $\mathrm{C}_{60}$ fluorescence quantum yields, on the other hand.

In principle two competing deactivation processes, that is, energy transfer to $\mathrm{Fc}$ or accelerated intersystem-crossing 

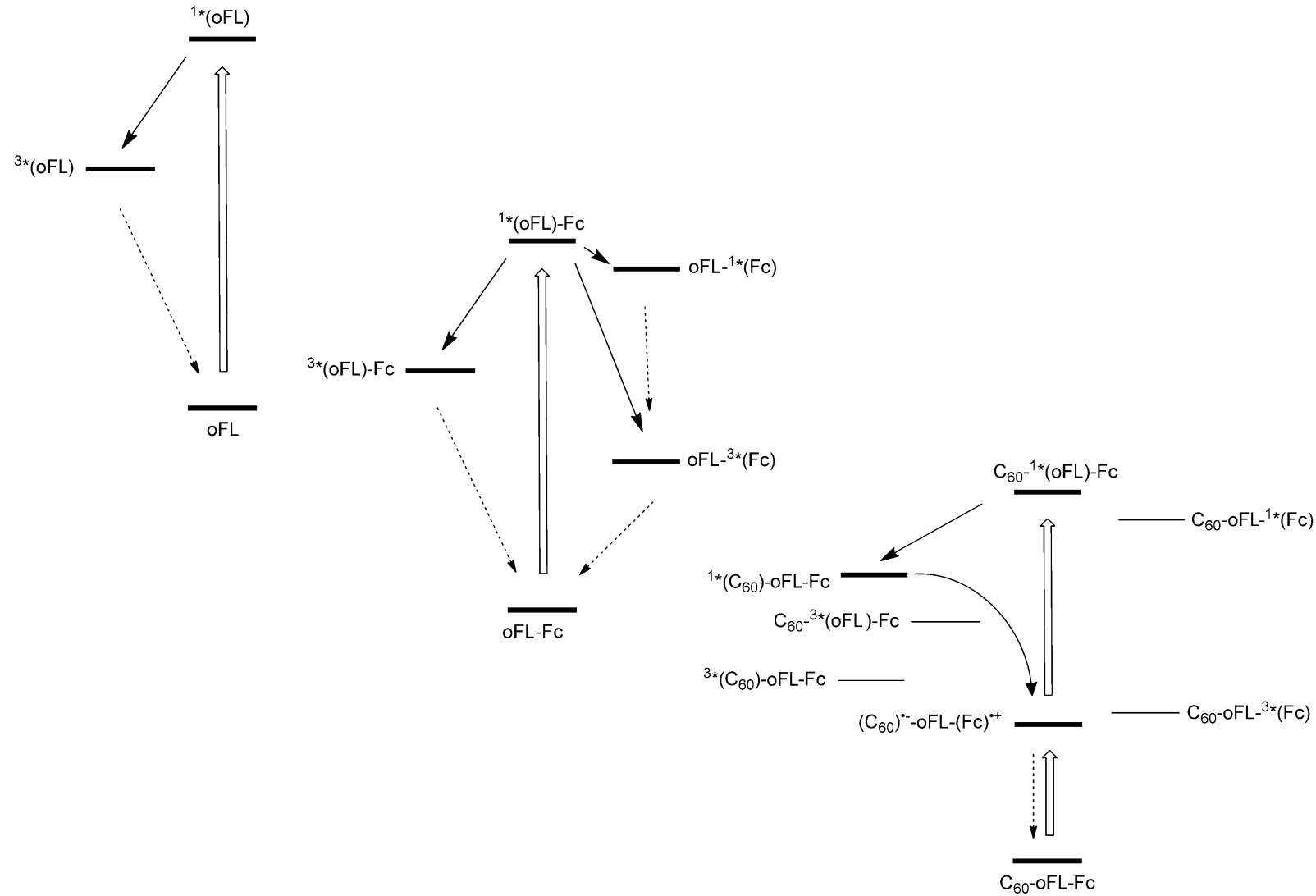

Scheme 4. Various deactivation patterns for the singlet-excited-state deactivation in oFL (top, left hand side), oFL-Fc (center), and $\mathrm{C}_{60}-\mathrm{oFL}-\mathrm{Fc}$ (lower, right hand side). Solid arrows indicate initial processes, dashed arrows indicate subsequent processes, thick lines indicate participating states, and thin lines indicate non-participating states.

due to iron, are energetically feasible. ${ }^{[31,32]}$ With respect to the earlier pathway, only formation of the Fc triplet excitedstate at as low as $1.12 \mathrm{eV}$ is within reach, since the Fc singlet excited-state lies unreachable at around $2.5 \mathrm{eV} .^{[33]}$ Under similar experimental conditions, very weak absorption changes in, for example, the 500 to $760 \mathrm{~nm}$ range ${ }^{[34]}$ and a lifetime of $600 \mathrm{ps}$ were noted for the Fc triplet excited state in a Fc reference. ${ }^{[35]}$ Of importance is the spectral mismatch between what is illustrated in Figure 7 and the Fc triplet excited-state. As far as the latter pathway is concerned, the $\mathrm{C}_{60}$ triplet excited-state $(1.5 \mathrm{eV})$ in the form of the $690 \mathrm{~nm}$ feature should be seen. However, the lack of it leads us to rule out any meaningful contribution from this deactivation channel. The above experiments, considered in concert, indicate that these deactivation pathways are at best minor contributions in the overall deactivation of the $\mathrm{C}_{60}$ singlet excited-state.

From the first-order fitting of the $\mathrm{C}_{60}{ }^{-}$and $\mathrm{Fc}^{\circ+}$ radicalion-pair state formation kinetics, the corresponding chargeseparation rate constants were derived (Table 3). Importantly, the charge-separation dynamics depend not only on the overall electron-donor-acceptor distance, but also on the respective linkages that connect $\mathrm{Fc}$ and the oFL part of the bridge. For example, compounds $\mathbf{1}$ and $\mathbf{2}$ show accelerated dynamics of charge separation. In $\mathbf{1}$, the short electron- donor-acceptor distance is responsible for this trend, whereas in $\mathbf{2}$ the acceleration originates from the improved overlap of the $\pi$-orbitals due to the triple bond and largest $\beta$ values. In the bifluorenyl structures $\mathbf{1 b}, \mathbf{2 b}, \mathbf{3 b}$, and $\mathbf{4 b}$, the differences in the charge-separation dynamics are modulated, owing to the fact that the distance between donor and acceptor governs the charge transfer.

The lifetimes of the radical-ion-pair states are relatively short with values of up to $2.3 \mathrm{~ns}$ in $\mathbf{4 b}$. As shown, not only a significant distance dependence, but also the geometrical properties, govern the charge recombination. Hence, the long charge-separation lifetime in $\mathbf{4 b}$ is due to the longest electron-donor-acceptor distance and the larger dihedral angles, which block the charge recombination. Furthermore, the distance dependence becomes crucial when going from only one FL to two FLs: more than a ten-fold increase of the radical-ion-pair lifetime is observed in all the conjugates 1-4. In accordance with the geometries and orbital representations from the molecular modeling, the second FL unit adopts a dihedral angle of approximately $40^{\circ}$ relative to the first FL. Hence, the bridge between $\mathrm{C}_{60}$ and $\mathrm{Fc}$ loses its planarity leading to a deceleration of the charge recombination. Furthermore, the HOMO-2 and HOMO-4 (Supporting Information, Figure S1) become involved in the charge-transfer process, which underlines the augmented role of the 

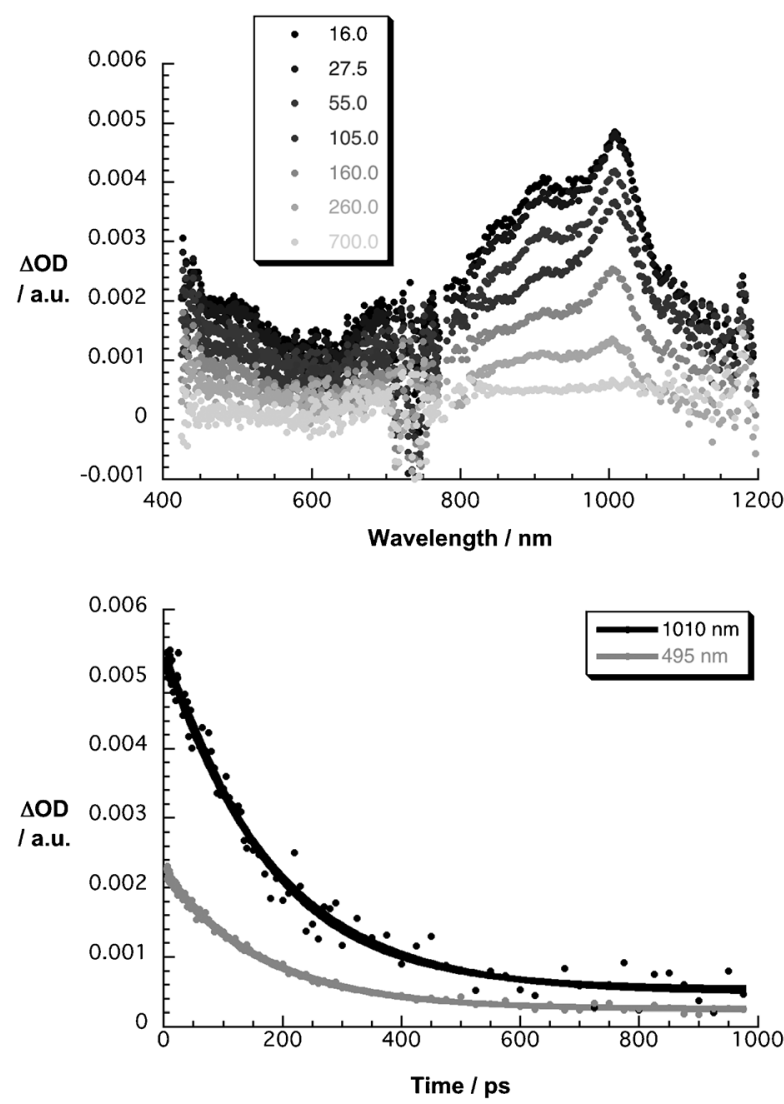

Figure 7. Upper part: differential absorption spectra (visible and near-infrared) obtained upon femtosecond flash photolysis $(387 \mathrm{~nm}, 100 \mathrm{~nJ})$ of 4a in argon-saturated THF with time delays between 16.0 and $700 \mathrm{ps}$ at room temperature. Lower part: absorption-time profiles at 495 and $1010 \mathrm{~nm}$ monitoring the charge separation and charge recombination.

bridge upon increasing the length. In the mono-FL systems 1a-4a, the linkage between Fc and FL impacts the charge recombination due to the imposed structural features that are seen to dominate the charge separation, with $\mathbf{1 a}$ and $\mathbf{3 a}$ showing an accelerated charge-recombination.

Summarizing the charge separation and charge recombination rates in THF and analyzing their dependence on the electron-donor-acceptor separation established the attenuation factors. Figure 8 exemplifies the dependence of the charge-transfer rates on the electron-donor-acceptor distances for 4 . The different $\beta$ values listed in Table 4 were determined from the slopes of the linear fits for all the systems. With the exception of $\mathbf{2}$, the established $\beta$ values for charge separation are in the range of those formerly established for oFLs, ${ }^{[23]}$ namely $0.09 \AA^{-1}$. Importantly, whereas the charge separation seems to occur rather independently of the distance, the linker between Fc and oFL significantly impacts the charge-separation rates. In particular, the above mentioned structural and electronic features with regard to the extension of the $\pi$-system and the orbital overlap between Fc and oFL are reflected in the different $\beta$ values for charge separation. In fact, $\mathbf{3}$ exhibits the lowest value for $\beta$ and $\mathbf{2}$ the highest value. Interestingly, the charge recombination

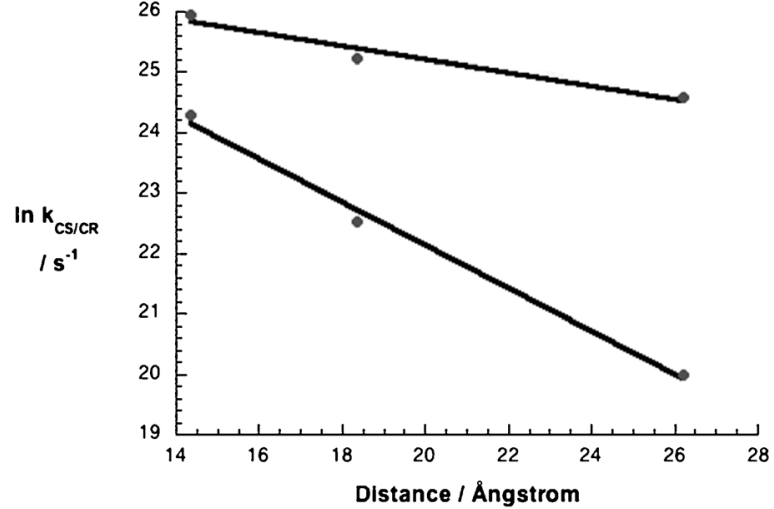

Figure 8. Representation of the charge-separation $\left(\ln k_{\mathrm{CS}}\right)$ and charge-recombination $\left(\ln k_{\mathrm{CR}}\right)$ rate constants on the center-to-center distances $\left(R_{\mathrm{CC}}\right)$ in nitrogen-saturated THF at room temperature for 4 . The slopes represent the different $\beta$ values for charge separation (black) and charge recombination (gray).

Table 4. The $\beta$ values $\left[\AA^{-1}\right]$ for charge separation (CS) and charge recombination (CR) as resulted from the plots of the charge-separation $\left(\ln k_{\mathrm{CS}}\right)$ and charge-recombination $\left(\ln k_{\mathrm{CR}}\right)$ rate constants on the centerto-center distances $\left(R_{\mathrm{CC}}\right)$ in nitrogen-saturated THF (Figure 8).

\begin{tabular}{lll}
\hline & $\beta_{\mathrm{CS}}$ & $\beta_{\mathrm{CR}}$ \\
\hline $\mathbf{1 a}, \mathbf{b}$ & 0.10 & 0.35 \\
$\mathbf{2 a}, \mathbf{b}$ & 0.19 & 0.36 \\
$\mathbf{3 a}, \mathbf{b}$ & 0.08 & 0.34 \\
$\mathbf{4 a , b}$ & 0.11 & 0.36 \\
\hline
\end{tabular}

depends strongly on the donor-acceptor distance, but not at all on the linkage. For all systems a value of $\beta_{\mathrm{CR}}(0.35 \pm$ $0.01) \AA^{-1}$ was established. As aforementioned, the second FL slows down the charge recombination by a factor of ten due to the $40^{\circ}$ dihedral angle between the two FLs. This breaks the conjugation between the donor and acceptor and leads to an energetic barrier. The difference in $\beta$ values between charge separation and charge recombination results from the fact that both occur through different sets of orbitals.

\section{Conclusion}

A series of new Fc-linker-oFL ${ }_{n}-\mathrm{C}_{60}(n=1,2)$ conjugates, in which oFL bridges are bound through various linkers to electron-donating ferrocene and electron-accepting $\mathrm{C}_{60}$, has been synthesized and characterized. In these systems the linker is either a single bond, ethyne, vinylene or a phenylene unit. Summarizing, it has been shown that structural alterations of these linkers readily change the dihedral angles between the Fcs and the oFLs and, hence, impact the orbital overlap. In this way, it was possible to tune, with precision, the intramolecular charge-transfer characteristics by variations of the linkers without interfering with the electronic communication between the two electroactive units, namely $\mathrm{Fc}$ and $\mathrm{C}_{60}$. In fact, charge injection into the bridge is con- 
trolled by structural arrangements imposed by the linkages, which can be viewed as a bottleneck to this process.

Photoexcitation of either Fc or oFL moieties in THF and benzonitrile results in intramolecular charge-transfer over distances beyond $26 \AA$ from the electron-donating Fcs to the electron-accepting $\mathrm{C}_{60}$. Competing processes such as energy transfer to $\mathrm{Fc}$ or accelerated intersystem-crossing play no significant role. The photophysical and quantum chemical characterization of these $\mathrm{Fc}$-linker-oFL ${ }_{n}-\mathrm{C}_{60}$ systems qualitatively and quantitatively corroborates the influence of the structural parameters on the intramolecular charge-transfer processes. Correlating the dynamics of intramolecular charge-separation/charge-recombination with the electrondonor-acceptor distances resulted in different attenuation factors for charge separation and charge recombination. Specifically, intramolecular charge-separation depends strongly on the linker and only weakly on the donor-acceptor distance. Intramolecular charge-recombination, on the other hand, depends strongly on the D-A distance and is independent of the linker. These findings imply that the intramolecular charge-separation and charge-recombination must occur through different sets of orbitals. The experimental results have been corroborated by using molecular modeling studies. This work establishes that oFLs are excellent bridging sub-units for fine-tuning intramolecular charge-transport, not only in electron-donor-bridge-acceptor conjugates but very likely also between photoexcited chromophores and wide band-gap semiconductors in, for example, dye-sensitized solar cells. ${ }^{[36,37]}$ Still, future experiments need to confirm the applicability of the current results to oPV- and oPE-based D-B-A systems.

\section{Experimental Section}

UV/Vis spectroscopy: Lambda $2 \mathrm{UV} / \mathrm{Vis}$ spectrophotometer (PerkinElmer); absorption maxima $\lambda_{\max }$ given in $\mathrm{nm}$.

Steady state fluorescence spectroscopy: Horiba Jobin Yvon Fluoromax 3 spectrophotometer; at room temperature $(298 \mathrm{~K})$ in a 1 to $1 \mathrm{~cm}$ quartz cuvette. All spectra were corrected for the instrument response. For excitation wavelength below $450 \mathrm{~nm}$ a cut off filter $(435 \mathrm{~nm})$ was inserted. For the determination of fluorescence quantum yields $\mathrm{NMPC}_{60}$ and $\mathrm{oFL}_{2}$ were used as reference compounds regarding $\mathrm{C}_{60}$ and oFL emission, respectively.

Fs-transient absorption spectroscopy: Femtosecond transient absorption studies were performed with $387 \mathrm{~nm}$ laser pulses $(1 \mathrm{kHz}, 150 \mathrm{fs}$ pulse width) from an amplified Ti/sapphire laser system (Model CPA 2101, Clark-MXR Inc.; output $775 \mathrm{~nm}$ ). For an excitation wavelength of $420 \mathrm{~nm}$, a nonlinear optical parametric converter (NOPA) was used to generate ultra-short tunable visible pulses out of the pump pulses. The transient absorption pump probe spectrometer (TAPPS) is referred to as a two-beam setup, in which the pump pulse is used as excitation source for transient species and the delay of the probe pulse is exactly controlled by an optical delay rail. As the probe (white-light continuum), a small fraction of pulses stemming from the CPA laser system was focused by a $50 \mathrm{~mm}$ lens into a $2 \mathrm{~mm}$ thick sapphire disc. The transient spectra were recorded using fresh oxygen-free solutions in each laser excitation. All experiments were performed at $298 \mathrm{~K}$ in a $2 \mathrm{~mm}$ quartz cuvette.

\section{Acknowledgements}

This work was supported by the EC FP7 ITN "FUNMOLS" project no. 212942. M.W. and J.E.M. acknowledge financial support by the NCCR MUST, a research instrument of the Swiss National Science Foundation.

[1] W. W. Parson, Photosynth. Res. 2003, 76, 81-92.

[2] a) C. J. Brabec, N. S. Sariciftci, J. C. Hummelen, Adv. Funct. Mater. 2001, 11, 15-26; b) K. M. Coakley, M. D. McGehee, Chem. Mater 2004, 16, 4533-4542; c) S. Günes, H. Neugebauer, N. S. Sariciftci, Chem. Rev. 2007, 107, 1324-1338; d) B. C. Thompson, J. M. Fréchet, Angew. Chem. 2008, 120, 62-82; Angew. Chem. Int. Ed. 2008, 47, 58-77; e) G. Dennler, M. C. Scharber, C. J. Brabec, Adv. Mater 2009, 21, 1323-1338; f) B. Kippelen, J. L. Brédas, Energy Environ. Sci. 2009, 2, 251-261; g) J. L. Delgado, P. A. Bouit, S. Filippone, M. A. Herranz, N. Martín, Chem. Commun. 2010, 46, 4853-4865; h) Special Issue on Organic Electronics, Chem. Mater. 2004, 16, 4381-4846; i) Special Issue on Organics and Optoelectronics, Chem. Rev. 2007, 107, 923-1386.

[3] a) J. M. Tour, Chem. Rev. 1996, 96, 537-553; b) Y. Shirota, J. Mater Chem. 2000, 10,1-25; c) J. Roncali, Acc. Chem. Res. 2000, 33, 147156; d) J. L. Segura, N. Martín, J. Mater. Chem. 2000, 10, 2403-2435; e) N. Martín, L. Sánchez, M. A. Herranz, B. Illescas, D. M. Guldi, Acc. Chem. Res. 2007, 40, 1015-1024; f) R. A. Wassel, C. B. Gorman, Angew. Chem. 2004, 116, 5230-5233; Angew. Chem. Int. Ed. 2004, 43, 5120-5123; g) R. L. Carroll, C. B. Gorman, Angew. Chem. 2002, 114, 4556-4579; Angew. Chem. Int. Ed. 2002, 41, 4378 4400; h) J. L. Segura, N. Martín, D. M. Guldi, Chem. Soc. Rev. 2005, $34,31-47$.

[4] a) M. R. Wasielewski, Chem. Rev. 1992, 92, 435-461; b) M. R. Wasielewski, J. Org. Chem. 2006, 71, 5051-5066.

[5] a) P. A. Van Hal, S. C. J. Meskers, R. A. J. Janssen, Appl. Phys. A 2004, 79, 41-46; b) G. de La Torre, F. Giacalone, J. L. Segura, N Martin, D. M. Guldi, Chem. Eur. J. 2005, 11, 1267-1280; c) T. M. Figueira-Duarte, A. Gégout, J. F. Nierengarten, Chem. Commun. 2007, 109-119; d) T. L. J. Toivonen, T. I. A. Hukka, J. Phys. Chem. A 2007, 111, 4821-4828; e) J. Santos, B. M. Illescas, M. Wielopolski, A. M. G. Silva, A. C. Tomé, D. M. Guldi, N. Martín, Tetrahedron 2008, 64, 11404-11408.

[6] a) J. F. Nierengarten, T. Gu, T. Aernouts, W. Green, J. Poortmans, G. Hadziioannou, D. Tsamouras, Appl. Phys. A 2004, 79, 47-49; b) K Koynov, A. Bahtiar, C. Bubeck, B. Mühling, H. Meier, J. Phys. Chem. B 2005, 109, 10184-10188; c) Y. Zhao, Y. Shirai, A. D. Slepkov, L. Cheng, L. B. Alemany, T. Sasaki, F. A. Hegmann, J. M. Tour, Chem. Eur. J. 2005, 11, 3643-3658; d) J. Fortage, E. Göransonn, E. Blart, H. C. Becker, L. Hammarström, F. Odobel, Chem. Commun 2007, 4629-4631; e) K. Y. Pu, X. Y. Qi, Y. L. Yang, X. M. Lu, T. C. Li, Q. L. Fan, C. Whang, B. Liu, H. S. O. Chan, W. Huang, Chem. Eur. J. 2008, 14, 1205-1215; f) A. Lembo, P. Tagliatesta, D. M Guldi, M. Wielopolski, M. Nuccetelli, J. Phys. Chem. A 2009, 113, 1779-1793.

[7] a) M. Wielopolski, G. Rojas, C. van der Pol, L. Brinkhaus, G. Katsukis, M. R. Bryce, T. Clark, D. M. Guldi, ACS Nano 2010, 4, 6449 6462 ; b) M. E. Walther, J. Grilj, D. Hanss, E. Vauthey, O. S. Wenger, Eur. J. Inorg. Chem. 2010, 4843-4850.

[8] a) S. A. Vail, P. J. Krawczuk, D. M. Guldi, A. Palkar, L. Echegoyen, J. P. C. Tomé, M. A. Fazio, D. I. Schuster, Chem. Eur. J. 2005, 11 , 3375-3388; b) S. A. Vail, D. I. Schuster, D. M. Guldi, M. Isosomppi, N. Tkachenko, H. Lemmetyinen, A. Palkar, L. Echegoyen, X. Chen, J. Z. H. Zhang, J. Phys. Chem. B 2006, 110, 14155-14166; c) C. Wang, L.-O. Pålsson, A. S. Batsanov, M. R. Bryce, J. Am. Chem. Soc. 2006, 128, 3789-3799; d) L.-O. Pålsson, C. Wang, A. S. Batsanov, S. M. King, A. Beeby, A. P. Monkman, M. R. Bryce, Chem. Eur. J. 2010, 16, 1470-1479.

[9] a) T. Nakamura, M. Fujitsuka, Y. Araki, I. Osamu, J. Ikemoto, K Takimiya, Y. Aso, T. Otsubo, J. Phys. Chem. B 2004, 108, 10700 10710; b) C. H. Huang, N. D. McClenaghan, A. Kuhn, J. W. Hofstraat, D. M. Bassani, Org. Lett. 2005, 7, 3409-3412; c) A. Petrella, 
J. Cremer, L. De Cola, P. Bäuerle, R. M. Williams, J. Phys. Chem. A 2005, 109, 11687-11695; d) M. Narutaki, K. Takimiya, T. Otsubo, Y. Harima, H. Zhang, Y. Araki, I. Osamu, J. Org. Chem. 2006, 71, $1761-1768$.

[10] F. Oswald, D. M. S. Islam, Y. Araki, V. Troiani, R. Caballero, P. de La Cruz, O. Ito, F. Langa, Chem. Commun. 2007, 4498-4500.

[11] H. U. Winters, E. Dahlstedt, H. E. Blades, C. J. Wilson, M. J. Frampton, H. L. Anderson, B. Albinsson, J. Am. Chem. Soc. 2007, 129, $4291-4297$.

[12] a) F. Barigelletti, L. Flamigni, M. Guardigli, A. Juris, M. Beley, S. Chodorowski-Kimmes, J.-P. Collin, J.-P. Sauvage, Inorg. Chem. 1996, 35, 136-142; b) A. J. Berresheim, M. Müller, K. Müllen, Chem. Rev. 1999, 99, 1747-1786; c) B. Schlicke, P. Belser, L. De Cola, E. Sabbioni, V. Balzani, J. Am. Chem. Soc. 1999, 121, 4207-4214; d) A. Helms, D. Heiler, G. McLendon, J. Am. Chem. Soc. 1992, 114, 6227-6238; e) R. Cohen, K. Stokbro, J. M. L. Martin, M. A. Ratner, J. Phys. Chem. C 2007, 111, 14893-14902.

[13] E. A. Weiss, M. R. Wasielewski, M. A. Ratner, Top. Curr. Chem. 2005, 257, 103-133.

[14] D. M. Guldi, B. M. Illescas, C. M. Atienza, M. Wielopolski, N. Martín, Chem. Soc. Rev. 2009, 38, 1587-1597.

[15] L. De Cola, in Top. Curr. Chem. Vol. 257, Springer, Heidelberg, 2005, pp. 63-103.

[16] W. B. Davis, W. A. Svec, M. A. Ratner, M. R. Wasielewski, Nature 1998, 396, 60-63.

[17] E. A. Weiss, M. J. Ahrens, L. E. Sinks, A. V. Gusev, M. A. Ratner, M. R. Wasielewski, J. Am. Chem. Soc. 2004, 126, 5577-5584.

[18] R. H. Goldsmith, L. E. Sinks, R. F. Kelley, L. E. Betzen, W. H. Liu, E. A. Weiss, M. A. Ratner, M. R. Wasielewski, Proc. Natl. Acad. Sci. USA 2005, 102, 3540-3545.

[19] A. M. Scott, A. B. Ricks, M. T. Colvin, M. R. Wasielewski, Angew. Chem. 2010, 122, 2966-2970; Angew. Chem. Int. Ed. 2010, 49, $2904-$ 2908.

[20] A. M. Scott, T. Miura, A. B. Ricks, A. E. X. Dance, E. M. Giacobbe, M. T. Colvin, M. R. Wasielewski, J. Am. Chem. Soc. 2009, 131, 17655-17666.

[21] M. P. Eng, B. Albinsson, Angew. Chem. 2006, 118, 5754-5757; Angew. Chem. Int. Ed. 2006, 45, 5626-5629.

[22] M. Wielopolski, J. Santos, B. M. Illescas, A. Ortiz, B. Insuasty, T. Bauer, D. M. Guldi, N. Martín, Energy Environ. Sci. 2011, 4, 765771.

[23] C. Atienza-Castellanos, M. Wielopolski, D. M. Guldi, C. van der Pol, M. R. Bryce, S. Filippone, N. Martín, Chem. Commun. 2007, 51645166.

[24] a) M. Prato, M. Maggini, Acc. Chem. Res. 1998, 31, 519-526; b) M. Maggini, G. Scorrano, M. Prato, J. Am. Chem. Soc. 1993, 115, 97989799.
[25] C. van der Pol, M. R. Bryce, M. Wielopolski, C. Atienza-Castellanos D. M. Guldi, S. Fillipone, N. Martín, J. Org. Chem. 2007, 72, 66626671.

[26] a) Y. Zhao, D. G. Truhlar, Theor. Chem. Acc. 2008, 120, 215-241; b) Y. Zhao, D. G. Truhlar, Acc. Chem. Res. 2008, 41, 157-167.

[27] T. H. Dunning, P. J. Hay, in Modern Theoretical Chemistry Vol. 3 (Ed.: H. F. Schaefer), Plenum, New York, 1976, pp. 1-28.

[28] M. Dolg, U. Wedig, H. Stoll, H. Preuss, J. Chem. Phys. 1987, 86 $866-873$.

[29] R. Ditchfield, W. J. Hehre, J. A. Pople, J. Chem. Phys. 1971, 54, $724-$ 729; M. J. Frisch, J. A. Pople, J. S. Binkley, J. Chem. Phys. 1984, 80 , 3265-3269.

[30] Gaussian 09, Revision A.1, M. J. Frisch, G. W. Trucks, H. B. Schlegel, G. E. Scuseria, M. A. Robb, J. R. Cheeseman, G. Scalmani, V. Barone, B. Mennucci, G. A. Petersson, H. Nakatsuji, M. Caricato, X. Li, H. P. Hratchian, A. F. Izmaylov, J. Bloino, G. Zheng, J. L. Sonnenberg, M. Hada, M. Ehara, K. Toyota, R. Fukuda, J. Hasegawa, M. Ishida, T. Nakajima, Y. Honda, O. Kitao, H. Nakai, T. Vreven, J. A. Montgomery, Jr., J. E. Peralta, F. Ogliaro, M. Bearpark, J. J. Heyd, E. Brothers, K. N. Kudin, V. N. Staroverov, R. Kobayashi, J. Normand, K. Raghavachari, A. Rendell, J. C. Burant, S. S. Iyengar, J. Tomasi, M. Cossi, N. Rega, J. M. Millam, M. Klene, J. E. Knox, J. B. Cross, V. Bakken, C. Adamo, J. Jaramillo, R. Gomperts, R. E. Stratmann, O. Yazyev, A. J. Austin, R. Cammi, C. Pomelli, J. W. Ochterski, R. L. Martin, K. Morokuma, V. G. Zakrzewski, G. A. Voth, P. Salvador, J. J. Dannenberg, S. Dapprich, A. D. Daniels, Ö. Farkas, J. B. Foresman, J. V. Ortiz, J. Cioslowski, D. J. Fox, Gaussian, Inc., Wallingford CT, 2009.

[31] S.-H. Lee, A. G. Larsen, K. Ohkubo, Z.-L. Cai, J. R. Reimers, S. Fukuzumi, M. J. Crossley, Chem. Sci. 2012, 3, 257-269.

[32] T. M. Figueira-Duarte, Y. Rio, A. Listorti, B. Delavaux-Nicot, M. Holler, F. Marchioni, P. Ceroni, N. Armaroli, J.-F. Nierengarten, New J. Chem. 2008, 32, 54-64.

[33] V. Balzani, F. Bolletta, F. Scandola, J. Am. Chem. Soc. 1980, 102, 2152-2163.

[34] F. Hauke, A. Hirsch, S.-G. Liu, L. Echegoyen, A. Swartz, C. Luo, D. M. Guldi, ChemPhysChem 2002, 3, 195-205.

[35] A. Jaworska-Augustyniak, J. Karolczak, A. Maciejewski, J. Wojtczak, Chem. Phys. Lett. 1987, 137, 134-138.

[36] Z. Wan, C. Jia, Y. Duan, L. Zhou, Y. Lin, Y. Shia, J. Mater. Chem. 2012, 22, 25140-25147.

[37] W. M. Campbell, A. K. Burrel, D. L. Officer, K. W. Jolley, Coord. Chem. Rev. 2004, 248, 1363-1379.

Received: November 13, 2012 Revised: March 7, 2013 Published online: April 10, 2013 